Original Research Article

\title{
Efficacy and safety of bromocriptine quick release as an add on therapy with metformin and glipizide in type 2 diabetes mellitus patients: an open label randomized controlled study
}

\author{
Nithyapriya M. ${ }^{1}$, S. Purushotaman ${ }^{2 *}$
}

${ }^{1}$ Department of Pharmacology, Government Mohan kumara Mangalam Medical College, Salem, Tamil Nadu, India ${ }^{2}$ Department of Pharmacology, Department of Pharmacology, Madras Medical College, Chennai, Tamil Nadu, India

Received: 27 December 2018

Revised: 09 March 2019

Accepted: 11 March 2019

\section{*Correspondence to:}

Dr. S. Purushotaman,

Email: purush1312@gmail.com

Copyright: (C) the author(s), publisher and licensee Medip Academy. This is an openaccess article distributed under the terms of the Creative Commons Attribution NonCommercial License, which permits unrestricted noncommercial use, distribution, and reproduction in any medium, provided the original work is properly cited.

\begin{abstract}
Background: Type 2 Diabetes Mellitus (DM) is a metabolic disorder, treated by insulin and oral hypoglycaemic agents (OHA). Despite treatment, to protect diabetic population from its complications is difficult. So, there is a need for an OHA with different mechanism of action and minimal side effects. Bromocriptine Mesylate QR (Quick release) formulation was approved by FDA for treatment of type 2 DM. Hence, this study was planned to highlight the usefulness of Bromocriptine QR in type 2 diabetes mellitus.

Methods: Total 140 patients with type 2 DM were randomized into two groups. The control group was treated with Metformin $500 \mathrm{mg}$ BD (twice daily) and Glipizide $5 \mathrm{mg}$ BD for a period of 3 months. The study group received Bromocriptine quick release $1.6 \mathrm{mg}$ once daily, metformin $500 \mathrm{mg} \mathrm{BD}$ and Glipizide $5 \mathrm{mg} \mathrm{BD}$ for a period of 3 months. In both control and study groups, fasting blood glucose, postprandial blood glucose was monitored at $0,1^{\text {st }}, 2^{\text {nd }}$ and $3^{\text {rd }}$ month. HbA1C was done at baseline and at the end of 3 months.

Results: There was statistically significant decrease in fasting blood glucose, postprandial blood glucose and HbA1C when compared to baseline in both control group $(p<0.05)$ and study group $(p<0.05)$ at the end of 3 months. But the decrease in FBS, PPBS, HbA1C was higher in the study group $(\mathrm{p}=0.0001)$ than the control group $(\mathrm{p}=0.001)$.

Conclusions: In type 2 DM patients, Bromocriptine $\mathrm{QR}$, combined with metformin and Glipizide reduced fasting and postprandial blood glucose and $\mathrm{HbA} 1 \mathrm{C}$ significantly compared to metformin and glipizide alone.
\end{abstract}

Keywords: Bromocriptine, Glipizide, Metformin, Type 2 diabetes mellitus

\section{INTRODUCTION}

Diabetes Mellitus (DM) is becoming more common in both urban and rural population. Medical expenditures are high for treating diabetes mellitus and its complications. ${ }^{1}$ DM is a metabolic disorder characterized by chronic hyperglycaemia occurring as a result of insulin deficiency and insulin resistance. Among the various types of DM, Type $2 \mathrm{DM}$ is common globally and it is emerging as a key health problem. Insulin and oral hypoglycaemic drugs act to decrease insulin deficiency and insulin resistance. In spite of regular treatment, hyperglycaemia goes unchecked in many patients. Many drugs like sulphonylureas and thiazolidinediones are not used optimally because side effects limit their use. Insulin secretagogues can cause exhaustion of pancreas and decrease in insulin secretion on long term treatment. ${ }^{2}$ Inventions of new drugs are increasingly needed in the treatment of diabetes mellitus. Bromocriptine is a well-known drug for the treatment of parkinson's disease, hyperprolactinemia or acromegaly. 
Bromocriptine is a dopamine D2 receptor agonist. It inhibits pituitary secretion of prolactin. Bromocriptine also possesses partial D1-receptor agonist activity, 5-HT2 antagonist effects and mild adrenergic effects. ${ }^{3}$ Bromocriptine Mesylate QR (Quick release) formulation was approved by FDA in 2009 for treatment of Type 2 DM. ${ }^{4}$ The benefit of Bromocriptine in diabetes mellitus is through modulating central glucose and energy metabolism pathways. ${ }^{5,6}$

It can be used as monotherapy or as combination therapy to antidiabetic medications like metformin/sulfonylurea. It is not recommended for the treatment of type-1 diabetes or diabetic ketoacidosis. Bromocriptine is administered within two hours of awakening as a quick release formulation. It augments the hypothalamic dopamine levels which are low in DM and prevent undue sympathetic tone in the central nervous system, thus suppresses hepatic glucose synthesis. As a consequence, there is reduction in post meal plasma glucose. ${ }^{7}$

The hypothesis behind obesity and insulin resistance is the thrifty gene hypothesis that is insulin resistance is an adaptive state of many vertebrate species in preparation for periods of hibernation, winter and famine. ${ }^{8}$ Animals then revert back to an insulin sensitive condition when there is abundance of food. These changes in body weight and insulin resistance depending on season are due to changes in hypothalamic neuroendocrine rhythms. ${ }^{9}$

In humans, similar change in these neuroendocrine rhythms results in the non-seasonal development of obesity. The Bromocriptine quick release variant is usually given in the morning to reimburse for morning dip of dopamine in type $2 \mathrm{DM}$. This Bromocriptine given in the morning augments this low hypothalamic dopamine levels and thereby inhibits the excessive sympathetic activity within the central nervous system. Quick-release BEC was approved by the US Food and Drug Administration for the management of T2DM. ${ }^{10-12}$ Bromocriptine apart from improving glycaemic control it reduced body fat stores, thus diminishing the need for oral hypoglycaemic agents in obese type 2 diabetic patients. ${ }^{13}$

Several randomized controlled trials (mostly combining Bromocriptine with other oral glucose lowering medication) showed a significant reduction in several metabolic parameters such as a $0.4-0.7 \%$ reduction in HbA1c. ${ }^{14}$ More studies are needed to evaluate the efficacy and safety of Bromocriptine in diabetic population of Tamil Nadu, India. Hence, this study was done to evaluate the efficacy and safety of Bromocriptine in patients with diabetes mellitus coming to diabetic outpatient Department of Chengalpattu Medical College and Hospital, Tamil Nadu, India.

\section{METHODS}

Present study was a prospective, open labelled, comparative, randomized controlled study, conducted after approval from institutional ethical committee and as per the GCP guidelines. The study was conducted between 2014-2015. Subjects were recruited from patients with Type 2 DM attending diabetic OPD, Department of General medicine, Government Chengalpattu medical college and Hospital, Chengalpattu, Tamil Nadu, India. Sample Size was 60 patients in each group.

Both male and female patients of age 30-60 years, who are willing to give informed consent and known T2DM for more than 5 years, patients with fasting blood sugar more than $126 \mathrm{mg} \%$ and post prandial blood sugar more than $200 \mathrm{mg} \%$, taking metformin $500 \mathrm{mg}$ BD and glipizide 5 mg BD were included. All cases of Type 1 DM, Pregnant and lactating women, age $<30$ years and $>60$ years, patients with FBS $>300 \mathrm{mg} / \mathrm{dl}$ and PPBS $>400 \mathrm{mg} / \mathrm{dl}$ and $\mathrm{HbA} 1 \mathrm{C}>10 \%$, patients in whom insulin was indicated for treatment, patients associated with renal and liver disease, patients with coronary arterial disease, CCF, migraine, peripheral vascular disease, patients with known hypertension $\mathrm{BP}>140 / 90 \mathrm{mmHg}$, any concurrent intake of sympathomimetic drugs, any other serious medical or surgical illness were excluded from the study.

After screening 200 patients, 130 who fulfilled the selection criteria were recruited for the study. In this study, diabetic patients were randomly allocated in to two groups. All the odd number patients were allocated into control group and all the even number of patients were allocated into study group. After baseline investigations and clinical examination, the study group patients already on metformin $500 \mathrm{mg} \mathrm{BD}$ and Glipizide $5 \mathrm{mg}$ BD were added Bromocriptine $1.6 \mathrm{mg}$ OD for a period of 12 weeks. Bromocriptine Priscription was daily morning Bromocriptine $0.8 \mathrm{mg}$ OD within $2 \mathrm{hrs}$ of waking, for initial 1 week, followed by single morning dose of 1.6 $\mathrm{mg}$ /day within $2 \mathrm{hrs}$ of awaking for next 11 weeks. ${ }^{15}$ In the control group, patients already on metformin $500 \mathrm{mg}$ BD and Glipizide $5 \mathrm{mg}$ BD were continued with the same for next 12 weeks. At the end of every 2 weeks, patients were advised to return back the empty packs of medicines to assure compliance. After getting clinical history and clinical examination patients were given medicines for next 2 weeks. FBS, PPBS was done for each patient in the both study group and control group at baseline, $1^{\text {st }}$ month, $2^{\text {nd }}$ month and at $3^{\text {rd }}$ month. Body mass index estimation, Hba1c was done at baseline (at the start of the study) and at the end of the study for each patient in both study and control group.

At the end of 3 months, patients were advised to follow their regular drugs after the study and dosage adjusted according to their blood glucose level. Patients were monitored for any adverse effects for 2 weeks after withdrawal of Bromocriptine. Patients were advised to report any adverse effects immediately and at each visit to the investigator. Patients were advised to follow the diabetic diet chart, regular exercises and to stop smoking. Blood pressure monitoring, baseline laboratory investigations, chest X-ray, ECG were done and recorded 
for each patient at the start of the study and compared to the same tests done at the end of the study.

The data from investigations were collected, tabulated and analysed statistically. Statistical analysis was done with paired and unpaired t-test. Age distribution and sex distribution were analysed using Pearson Chi-square Test. Statistical package for social sciences SPSS 16 was used for statistical analysis of results.

\section{RESULTS}

In present study, fourteen patients were lost to follow up. 8 patients were withdrawn from the study due to side effects. Only 118 patients completed the study, results of those 118 patients were analysed statistically.

At the start of the study, no statistically significant difference was seen between study and control groups in age, sex distribution, FBS, PPBS, HbA1C before drug administration. There is statistically significant difference in mean FBS, PPBS and Hba1c between control and study groups at subsequent visits (students independent t test was used).

At the end of the study, in control group, decrease of mean FBS seen from baseline 188.17 to 164.6 (23.57) after 3 months. In study group, decrease of mean FBS seen from baseline 179.8 to 131.65 (48.15) after 3 months. When paired t-test was used to compare mean FBS before and after drug administration statistically significant reduction is seen in study group $(\mathrm{P}=0.0001)$ and also in control group $(\mathrm{P}=0.0001)$ at the end of the study. The reduction in the study group is higher $(\mathrm{p}=0.0001)$ than the control group $(\mathrm{p}=0.001)$ at the end of the study (Figure 1).

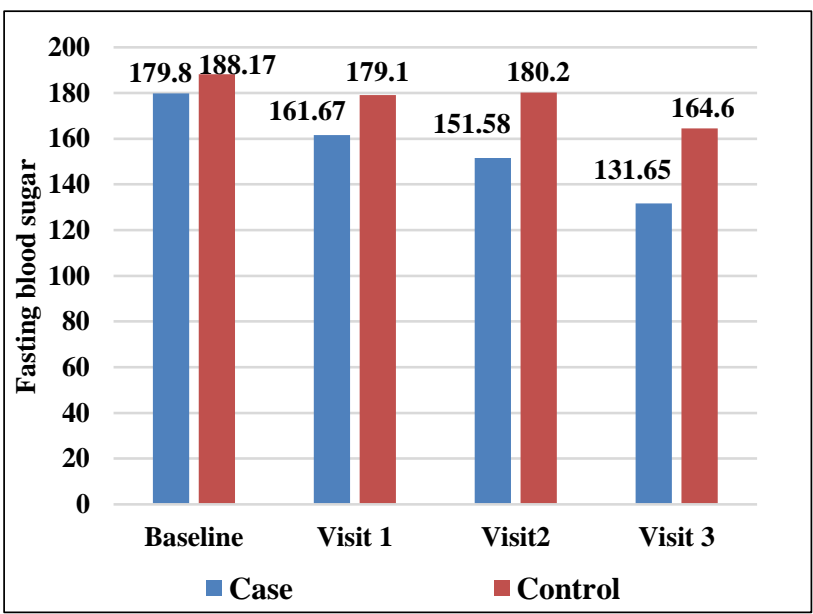

Figure 1: Fasting blood sugar of control and study.

In control group, decrease of mean PPBS seen from baseline 281.55 to 252.37 (29.18) after 3 months. In study group, decrease of mean PPBS seen from baseline 297.82 to 221.33 (76.49) after 3 months. When paired t-test was used to compare mean PPBS before and after drug administration statistically significant reduction is seen in study group at the end of the study $(\mathrm{P}=0.0001)$ and also in the control group $(\mathrm{p}=0.0001)$. The reduction of mean PPBS in the study group is higher $(\mathrm{p}=0.0001)$ than the control group $(\mathrm{p}=0.001)$ at the end of the study (Figure 2$)$.

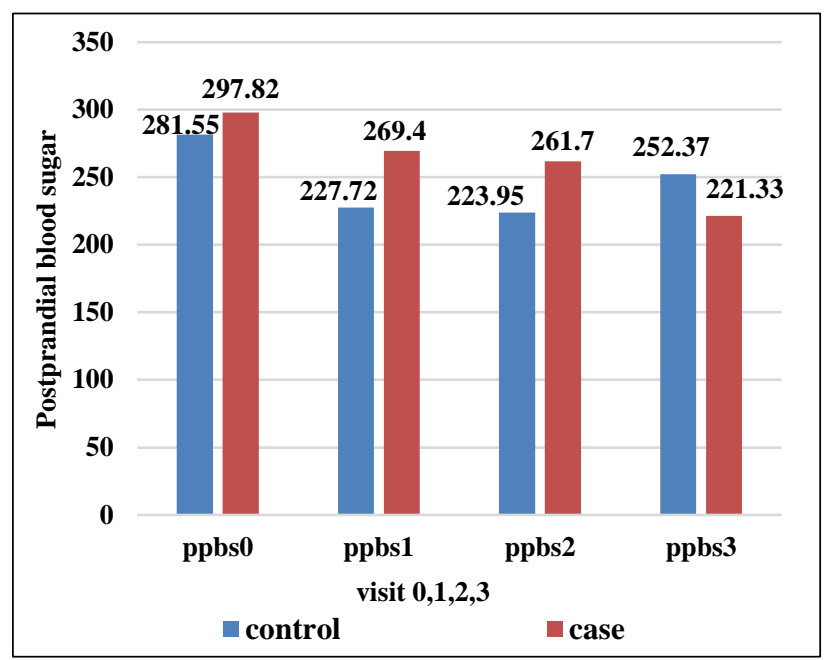

Figure 2: Postprandial blood sugar of control and study groups.

At the end of the study, there was a decrease in mean $\mathrm{HbA} 1 \mathrm{C}$ in both study and control groups. In control group, decrease of mean $\mathrm{HbA} 1 \mathrm{C}$ seen from baseline 7.63 to 7.32 (0.3) after 3 months. In study group, decrease of mean HbA1C seen from baseline 7.54 to 7.01 (0.5) after 3 months. When paired t-test was used to compare mean $\mathrm{HbA} 1 \mathrm{C}$ before and after drug administration statistically significant reduction was seen in the study group and in the control group at the end of the study. The reduction of mean HbA1C in the study group was higher $(\mathrm{p}=0.0001)$ than the control group $(\mathrm{p}=0.001)$ at the end of the study (Figure 3).

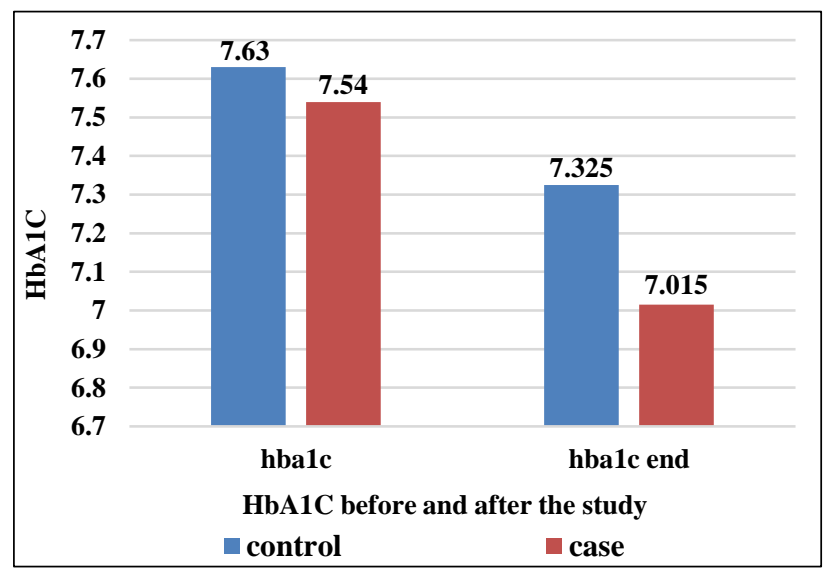

Figure 3: HbA1c before and after study in both groups.

The reduction of FBS, PPBS, HbA1C, in the study group was more than the reduction seen in the control group and it was statistically significant. Table 1 shows the comparison of adverse events among groups and their 
statistical significance. ${ }^{8}$ Patients withdrawn from the study due to adverse effects ( 3 in control group, 5 in study group). Of the 8 patients, 4 developed hypoglycaemia frequently ( 2 in group A, 2 in group B) and 4 patients had nausea and vomiting (1 in group A, 3 in group B). No statistically significant difference seen between the adverse effects of study and control groups.

Table 1: Comparisons of adverse events.

\begin{tabular}{|lllll|}
\hline \multirow{2}{*}{ Group } & \multicolumn{2}{l}{ Adverse events } & Total & $\begin{array}{l}\text { Chi-square } \\
\text { test }\end{array}$ \\
\cline { 1 - 4 } Control & 3 & 55 & 58 & $\mathrm{X}^{2}=0.42$ \\
\cline { 1 - 4 } & 5 & 55 & 60 & $\mathrm{P}=3.87$ \\
\hline
\end{tabular}

$* \mathrm{P} \leq 0.05$ significant, $* * \mathrm{P} \leq 0.01$ highly significant, $* * * \mathrm{P} \leq 0.001$ very highly significant.

\section{DISCUSSION}

Diabetes mellitus is becoming more common in both urban and rural population. Many drugs like Sulphonylureas and thiazolidinediones are not used optimally because side effects limit their use. In spite of regular treatment, hyperglycaemia goes unchecked in many patients. ${ }^{16}$ Inventions of new drugs are increasingly needed in the treatment of diabetes mellitus. Bromocriptine which is used in other conditions is found to be useful in diabetes mellitus. Clinical conditions like obesity, insulin resistance, hypertension and CKD reveal high NE plasma levels, sympathetic over activity and hyperprolactinemia which in turn was due to reduced dopaminergic tone. Dopamine agonists such as bromocriptine improve these clinical conditions. ${ }^{17-19}$ More studies are needed to evaluate the efficacy and safety of Bromocriptine in diabetic population of Tamil Nadu, India. Hence, this study was done to evaluate the efficacy and safety of Bromocriptine in patients with diabetes mellitus coming to diabetic Outpatient Department of Chengalpattu Medical College and Hospital, Tamil Nadu, India.

In this study, diabetic patients were divided in to two groups. Patients received Bromocriptine of $1.6 \mathrm{mg}$ in addition to Metformin and Glipizide in the study group and control group received only metformin and glipizide and the results were compared. The results of this present study showed, combination of Bromocriptine along with metformin and glipizide caused more reduction in FBS, PPBS and HbA1C than combination of metformin and glipizide alone.

Previous studies by Pijl $\mathrm{H}$ et al, showed there was a decrease in FBS to about $18 \mathrm{mg} / \mathrm{dl}$ in Bromocriptine group patients. ${ }^{20}$ Also studies by Pijl $\mathrm{H}$ et al, found patients on Bromocriptine group found a statistically significant reduction about $0.6 \%$ of $\mathrm{HbA} 1 \mathrm{c}$ compared to other groups. $^{20}$

Previous studies by Ramatke KB et al, shows reduction in mean FBS in bromocriptine+Metformin group about 44.31 $\mathrm{mg} / \mathrm{dl}$ at 12 weeks $(\mathrm{p}<0.05)$, reduction of PPBS about
$43.71 \mathrm{mg} / \mathrm{dl}$ at 12 weeks. ${ }^{21}$ ( $\left.\mathrm{P}<0.05\right)$ compared to baseline, which was statistically significant. Also, studies done by Ramatke $\mathrm{KB}$ et al, showed reduction in mean $\mathrm{HbA} 1 \mathrm{C}$ to about $0.74 \%$ in the group treated with Bromocriptine compared to the other groups $(\mathrm{P}<0.05) .{ }^{21}$ Another study done by Kamath $\mathrm{V}$ et al, shows the reduction in postprandial sugar was $16 \mathrm{mg} / \mathrm{dl}$ in the Bromocriptine group. $^{22}$

In this study, monitoring for adverse events also showed no major life-threatening adverse effects. Mild adverse effects like nausea, vomiting and hypoglycaemia occurred during the study period. There was no statistically significant difference between the adverse effects in the study and control groups.

So, Bromocriptine quick release is a safe drug that can be used in type 2 diabetes mellitus. It is available in India as tablet Bromocriptine Mesylate I.P equivalent to Bromocriptine $0.8 \mathrm{mg}$.

The results of this randomized open labelled clinical trial show in type 2 diabetes mellitus, add on therapy of Bromocriptine QR to Metformin and Glipizide in the study group, when compared to the control group of patients receiving Metformin and Glipizide alone, have caused significant reduction in the fasting blood sugar, postprandial blood sugar, HbA1C. There are no serious adverse effects observed in type 2 diabetes mellitus patients taking Bromocriptine QR 1.6 mg OD.

\section{CONCLUSION}

Bromocriptine is effective in reducing fasting blood glucose, postprandial blood glucose and HbA1c. Bromocriptine in doses used $1.6 \mathrm{mg} /$ day is found to be safe. No major adverse effects were seen during the use of Bromocriptine. Bromocriptine has advantages of not causing hypoglycaemia. Further, large-scale studies are necessary to highlight the effect of Bromocriptine on weight gain, lipid profile and hypertension.

\section{Funding: No funding sources}

Conflict of interest: None declared

Ethical approval: The study was approved by the Institutional Ethics Committee

\section{REFERENCES}

1. Ryan JG. Cost and policy implications from the increasing prevalence of obesity and diabetes mellitus. Gender Med. 2009;6:86-108.

2. Maedler K, Carr RD, Bosco D, Zuellig RA, Berney T, Donath MY. Sulfonylurea induced $\beta$-cell apoptosis in cultured human islets. J Clin Endocrinol Metab. 2005;90(1):501-6.

3. Deleu D, Northway MG, Hanssens Y. An evidencebased review of dopamine receptor agonists in the treatment of Parkinson's disease. Saudi Med J. 2002;23(10):1165-75. 
4. Mahajan R. Bromocriptine mesylate: FDA-approved novel treatment for type-2 diabetes. Ind J Pharmacol. 2009;41(4):197.

5. Kerr JL, Timpe EM, Petkewicz KA. Bromocriptine mesylate for glycemic management in type 2 diabetes mellitus. Ann Pharmacotherapy. 2010;44(11):177785.

6. Via MA, Chandra H, Araki T, Potenza MV, Skamagas M. Bromocriptine approved as the first medication to target dopamine activity to improve glycemic control in patients with type 2 diabetes. Diab Metab Syndrome Obes Targets Therapy. 2010;3:43.

7. DeFronzo RA. Bromocriptine: a sympatholytic, D2dopamine agonist for the treatment of type 2 diabetes. Diab Care. 2011;34(4):789-94.

8. Dowse G, Zimmet P. The thrifty genotype in noninsulin dependent diabetes. BMJ. 1993;306(6877):532.

9. Cincotta AH, Meier AH, Cincotta Jr M. Bromocriptine improves glycaemic control and serum lipid profile in obese type 2 diabetic subjects: a new approach in the treatment of diabetes. Expert Opinion Investigational Drugs. 1999;8(10):1683-707.

10. Pijl H, Ohashi S, Matsuda M, Miyazaki Y, Mahankali A, Kumar V, et al. Bromocriptine: a novel approach to the treatment of type 2 diabetes. Diab Care. 2000;23(8):1154-61.

11. Aminorroaya A, Janghorbani M, Ramezani M, Haghighi S, Amini M. Does bromocriptine improve glycemic control of obese type-2 diabetics?. Hormone Res Paediatrics. 2004;62(2):55-9.

12. Scranton R, Cincotta A. Bromocriptine-unique formulation of a dopamine agonist for the treatment of type 2 diabetes. Expert Opinion Pharmacotherapy. 2010;11(2):269-79.

13. Cincotta AH, Meier AH. Bromocriptine (Ergoset) reduces body weight and improves glucose tolerance in obese subjects. Diab Care. 1996;19(6):667-70.

14. Ghosh A, Sengupta N, Sahana P, Giri D, Sengupta P, Das N. Efficacy and safety of add on therapy of bromocriptine with metformin in Indian patients with type 2 diabetes mellitus: a randomized open labeled phase IV clinical trial. Ind $J$ Pharmacol. 2014;46(1):24

15. Shivaprasad C, Kalra S. Bromocriptine in type 2 diabetes mellitus. Ind $\mathbf{J}$ Endocrinol Metab. 2011;15(1):17.

16. American Diabetes Association. Standards of medical care for diabetes. Diab Care. 2008;31(1):S12-54.

17. Książek A, Załuska W. Sympathetic overactivity in uremia. J Renal Nutrition. 2008;18(1):118-21.

18. Kagan A, Gertler A, Ulman M, Bar-Khayim Y. Serum levels and peritoneal loss of prolactin in CAPD patients. In: Advances in peritoneal dialysis. Conference on Peritoneal Dialysis. 1991; 7: 247-252.

19. Wang GJ, Volkow ND, Logan J, Pappas NR, Wong $\mathrm{CT}, \mathrm{Zhu} \mathrm{W}$, et al. Brain dopamine and obesity. Lancet. 2001;357(9253):354-7.

20. Pijl H, Ohashi S, Matsuda M, Miyazaki Y, Mahankali A, Kumar V, et al. Bromocriptine: a novel approach to the treatment of type 2 diabetes. Diab Care. 2000;23(8):1154-61.

21. Ramteke KB, Ramanand SJ, Ramanand JB, Jain SS, Raparti GT, Patwardhan MH, et al. Evaluation of the efficacy and safety of bromocriptine QR in type 2 diabetes. Ind J Endocrinol Metab. 2011;15(1):S33.

22. Kamath V, Jones CN, Yip JC, Varasteh BB, Cincotta $\mathrm{AH}$, Reaven GM, et al. Effects of a quick-release form of bromocriptine (Ergoset) on fasting and postprandial plasma glucose, insulin, lipid, and lipoprotein concentrations in obese nondiabetic hyperinsulinemic women. Diab Care. 1997;20(11):1697-701.

Cite this article as: Nithyapriya M, Purushotaman S. Efficacy and safety of bromocriptine quick release as an add on therapy with metformin and glipizide in type 2 diabetes mellitus patients- an open label randomized controlled study. Int J Basic Clin Pharmacol 2019;8:669-73. 